\title{
MATHEMATICAL MODEL OF THE HEALD WITH DAMPING ELEMENT
}

\author{
Martin Bílek*, Josef Skřivánek \\ Department of Textile Machine Design of Technical University of Liberec, Liberec, \\ Czech Republic, Studentska 2, +420 485353174 \\ *e-mail: martin.bilek@tul.cz
}

\begin{abstract}
:
This study focuses on the analysis of the existing design solution of shedding mechanism. It is characterised by a heald attachment into the heald shaft with a necessary design allowance. The preparation of a mathematical model for the new concept of the heald attaching to the heald shaft frame is explained in this study. A damping element for dissipating the energy created during the heald impact on the carrying wire of the heald shaft is currently used for the high-speed weaving loom. This system makes use of a damping element, fitted in the profile of the rod at an optimum distance from heald eye. This element provides for reduction of the heald velocity before its drop upon the supporting wire because the opposite section of the heald is pressed into the rubber element. The calculated results of the new concept of the heald attaching to the heald shaft frame are compared with the existing solution without application of the damping element.
\end{abstract}

\section{Keywords:}

weaving loom, heald, mathematical model, analysis

\section{Introduction}

The principle of the production of fabric consists of inserting a transversal thread (the weft) into a system of longitudinal threads (the warp). The shedding motion together with a beatup mechanism represents the basic mechanisms of a loom, which ultimately decides the running speed and the quality of the fabric produced. These mechanisms jointly influence the dynamic behaviour of the machine as a whole. In order to interlace the yarns properly, the longitudinal threads must be divided into several systems in compliance with the required weave. Opening the system of the warp threads, we form the so-called shed - a wedge-shaped area necessary for insertion of the weft thread. The opening of the warp threads is provided for by the shedding motion. This mechanism converts the rotational motion of the main driving unit into a feed reverse motion of the operating element (the heald shaft). The main problem of presently used shedding motion and heald shafts is ensuring greater reliability and longer working life of different parts of shedding mechanism, like working life of heald shaft frames and namely of healds.

From a construction point of view, the lower and upper crossbeams and the edge-piece constitute the basic components of the heald shaft. The most important properties of the heald shaft frame are its rigidity and weight. When weaving, the flexion of the upper and lower crossbeams and their vibration must be minimal. The excessive weight of the shafts not only increases the loading on the shedding mechanism, but also has a negative influence on the shaft itself and on the length of its service life. The vibration of the shafts increases the noisiness of the loom and has a negative influence on the vibration of the loom and, thus, on the production of fabrics.

An important part of the heald shaft is the heddle and the method of its connection to the heald shaft. The individual threads of the warp are tied into the heddles. Because of the design of the heddles, it is not possible to allow (in the case of the present method of construction processing) loading of the heddles under tension. This would increase the probability of their destruction, leading to the interruption of the weaving process and subsequent economic losses. Considering the deformation of the upper and lower heald rods during the working cycle, it is necessary to anchor the heddle within the heald shaft frame with the necessary construction clearance. The movement of the sets of heddles occurs during the weaving cycle because the heald shaft carries out a reciprocating sliding motion. The subsequent dynamic impulse arising from the shift in the heddle set results in increased loading of the frame and the entire shedding mechanism. In the case of present arrangement of the heald shaft frame, the elastic forces of the warp threads are transferred to only one of the two heald rods, thanks to the heddle.

\section{Mathematical model of the shedding motion - heald}

It is necessary to deal with the description of the whole design chain when describing this part of the weaving loom: shedding mechanism - heald shaft - heald - warp. In general, the shedding mechanism can be classified into two sections: the driving section and the transforming section. The transforming section of the shedding mechanism consists of joint 
mechanisms usually, which convert the rotational motion of the driving section into a feed reverse motion of the heald shaft. The heald frame motion characteristics depend on the type of shedding motion. The course of load exerted upon the heald shaft depends upon the design of the parts of mechanism too.

The referred universal mathematical model of the shedding motion can be modified in a simple manner by entering the time-dependent lift dependence on the driving element, defining the course of its angular displacement. The analysis of driving section generated by rotary dobby or cam shedding motion is presented in [1-6].

In view of the fact that the transforming section of the shedding motion is a joint mechanism, a number of procedures and methods can be employed for modelling of the above structure [5-10]. It is possible to apply successfully the description of a mechanism based upon the method of devising motion equations by means of Lagrangian equations of the second type according to [10]. The concerned mathematical model is described with more details in [11, 12]. An experimental verification of the employed model of mechanical structure of the joint mechanism is described in $[13,14]$.

It is not possible to find a larger amount of the studies dealing with this theme in the case of the heald analysis and its attachment to the carrying wire. Some analyses have been dealt with in this process experimentally $[15,16]$. In order to be able to describe the behaviour of the heald during the weaving process, it is necessary to derive a suitable mathematical model that will describe its behaviour during the operating cycle with a defined precision. The heald is influenced by a number of forces that determine the supporting wire it will be coupled with. The most important ones are the dynamic force of the heald, the warp forces in the sense of movement of the shaft and the weight of the heald [17-19]. The simplest model of heald modelling solving its behaviour during the weaving process is described in [11]. However, this model is suitable for realisation of a basic analysis of behaviour of the system, precisely because of its simplicity. The basic outputs of the simple model are the moment of separation of the heald from the support wire, the time characterising the duration of the heald transfer between the rods of the heald shaft, the difference between the velocity of the heald and that of the supporting wire, etc. This mathematical model describing the behaviour of the heald during the weaving cycle simplified in this way can be used conveniently, namely for an analysis of principal parts of the shedding motion. It allows analysing the load distribution between the rods of the heald shaft during the weaving cycle. The said model allows determining principal areas of operating states of the heald and a simple analysis of the character of the heald transfer between rods of the heald shaft. Should the analysis be concerned with the behaviour of the heald during the weaving cycle directly, the mathematical model must be still extended and elaborated. For the generation of an improved mathematical model, the model with substitution of the rigidity of the heald by means of Kelvin-Voigt viscoelastic model has proved suitable [12]. The referred enhancement allows determining the number and extent of bounces of the heald from the supporting wire after its transfer between individual supporting wires. In this mathematical model, it is possible to ascertain the moment of separation of the heald from the supporting wire as well as the time of transfer of the heald between main beams of the heald shaft. By means of this model, it is possible to determine the loads exerted upon individual end eyelets of the heald. The affected calculations show a high value of acceleration of the heald produced after its drop upon the supporting wire.

With the products intended for high-speed weaving looms, some firms begin to employ a damping system of the drop of the heald upon the supporting wire. Vibrations that result in excessive wear of heald end loops and heald carrying rods are reduced. Durable damping strips of synthetic material are mounted in the frame stave profiles at an optimal distance in relation to the end loops. This damping system offers significant advantages over other alternatives in the market. (Figure. 1).

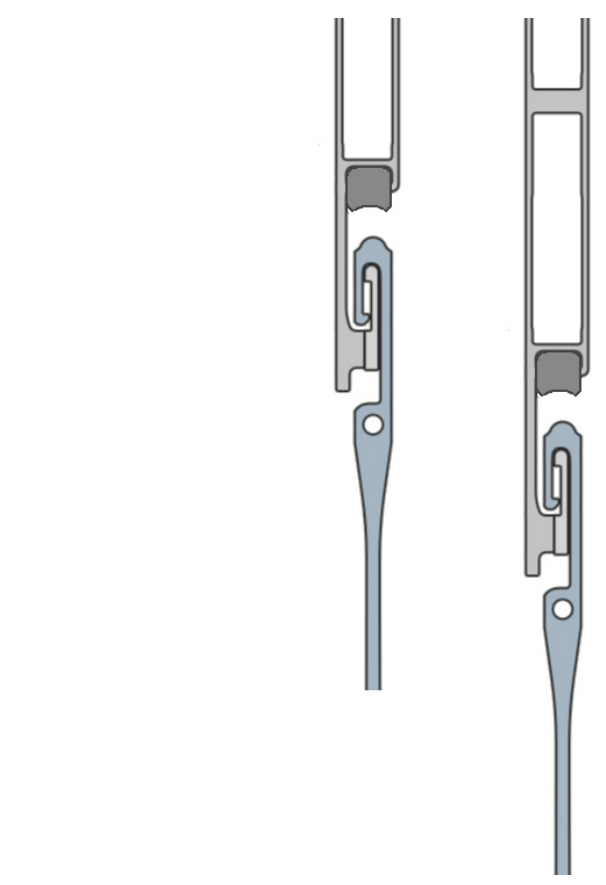

Figure 1 System of damping of heald

The mathematical model of the heald with a damping system is obtained by modifying the model of the elastic heald [12]. This model is complemented with the effect of the damping element. The whole solved system can be shown schematically according to the Figure 2. In the mathematical model, the play can be defined by means of the difference of positions of the upper and lower support wires. The distance of the lower support wire is shifted with respect to the position of the upper one by the extent of the fastening play. Thanks to this play, the forces in the warp threads are transmitted upon one of the couple of the rods of the heald shaft only. For the analysis of movement of the heald, we will assume that the frame of the shaft is rigid absolutely. In the mathematical model, this presumption will be reflected by the unchanging distance of both supporting wires during the course of the whole calculation, corresponding to the solution of movement of a heald fastened in the vicinity of the edge of a heald shaft. At present, the deformation of the main beams of the heald shaft during the working process are minimised by employing new types of composite rods. 


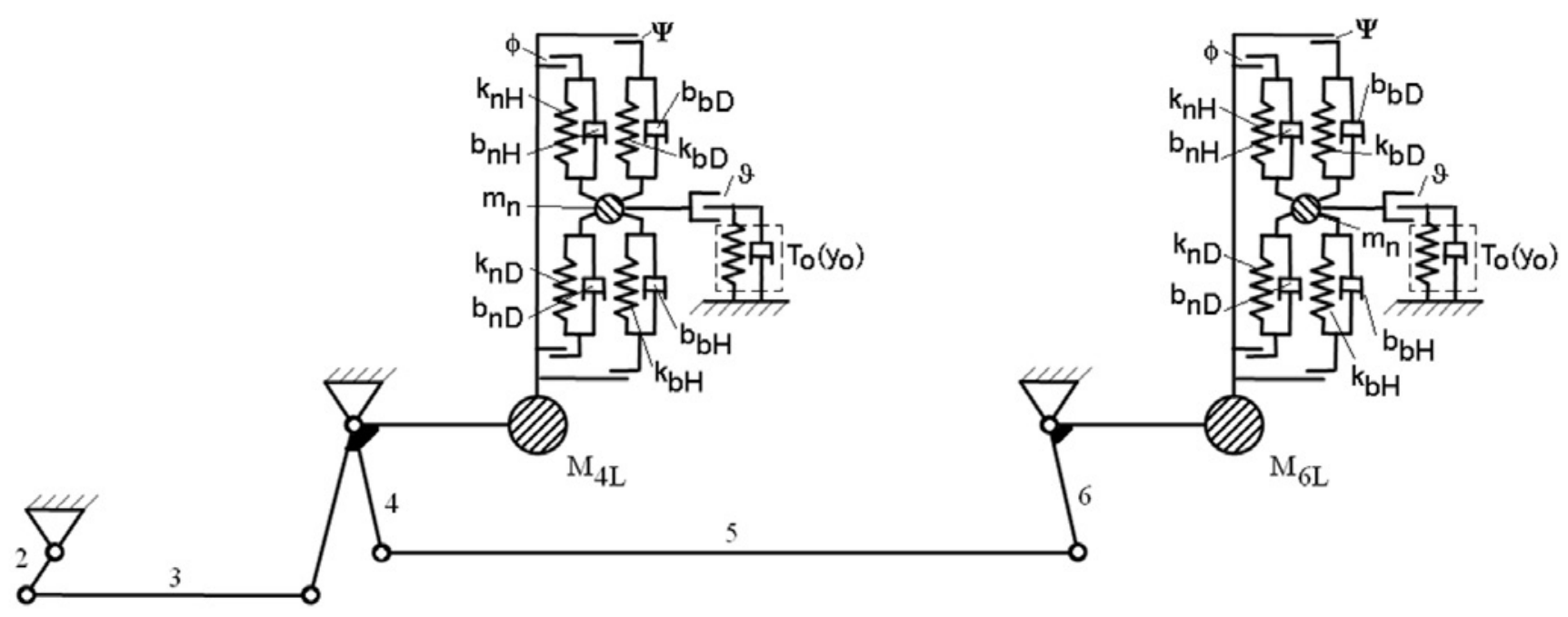

Figure 2 Schematic model of the system shedding motion - heald with damping element.

As mentioned in the introduction already, nowadays, flat healds made of a flat steel band by pressing process is employed. On the body of the heald, there are a number of orifices and stampings serving namely for drawing-in machines or for other technological purposes. These shape parameters influence upon its strength and stiffness. Some healds have a stamping in the position of one suspension eye that ought to provide for mutual spacing of healds; however, it reduces the stiffness of the suspension eye at the same time. Because of this reason, mathematical models have considered different rigidities of the upper and lower sections of the heald. In the mathematical model of the heald, we employ Newtonian impact theory. The description of the fall of the heald upon the supporting wire employs the presumption of a perfectly elastic impact. We presume the velocity of the fall of the heald upon supporting wire up to $1 \mathrm{~m} \mathrm{~s}^{-1}$.

The following part of the text describes the assembly of the model of a heald, by means of which we are able to find with which supporting wire the heald is coupled at a given moment. The motion equations describing the movement of the heald during the weaving process are complemented with motion equations of the shedding motion. The mass of the heald $\mathrm{mn}$ is concentrated in one particle in compiled model. The force To from the warp operates in the position of the thread eyelet. The mechanical properties of the yarn that is determined by the force of the warp in the mathematical model were determined experimentally [20-22]. The point of application of this force is located in one particle. It is possible to disregard the bowing of the heald due to its lateral loading. The derived models are based on the assumption that the movement of the particle substituting the heald is carried out in a straight line. In the solution of the system, the positions of the upper supporting wire and the lower one, and the position of the heald and position of the warp thread are established. The extent of the play in the fastening of the heald on the support wire is determined by the parameter $\mathrm{f}$. The compiled models of the heald also consider the effect of the dimension of the thread eyelet $\mathrm{J}$ upon the course of the force in the warp.
The general motion equation (1) describing the behaviour of the heald during a revolution of the weaving loom is complemented with further terms describing the stiffness and the effect of the damping element. The body of the heald is modelled by means of the Kelvin-Voigt viscoelastic model with the stiffness $\mathrm{knH}$ and co-efficient of viscous damping bnH in the upper part, and the stiffness $\mathrm{knD}$ and co-efficient of viscous damping bnD in the lower part of the heald. The parameter $Y$ determines the depth of heald nesting into the damping element before its drop upon the supporting wire. The stiffness $\mathrm{kbH}$ and the coefficient of viscous damping bbH characterise the properties of the damping strip in the upper section, whereas the stiffness $\mathrm{knD}$ and the co-efficient of viscous damping bnD characterise the properties of the damping strip in the lower section of the heald frame.

$$
\begin{aligned}
& m_{n} \cdot \ddot{y}_{i n}=T_{o}-m_{n} \cdot g+H \cdot k_{n H} \cdot\left(y_{h}-y_{n}\right)+H \cdot b_{n H} \cdot\left(\dot{y}_{h}-\dot{y}_{n}\right)- \\
& -D . k_{n D} \cdot\left(y_{n}-y_{d}\right)-D . b_{n D} \cdot\left(\dot{y}_{n}-\dot{y}_{d}\right)+H_{1} \cdot k_{b D} \cdot\left(y_{d}-y_{n}-\phi+\Psi\right)+ \\
& +H_{1} \cdot b_{b D} \cdot\left(\dot{y}_{d}-\dot{y}_{n}\right)-D_{1} \cdot k_{b H} \cdot\left(y_{n}-y_{h}-\phi+\Psi\right)-D_{1} \cdot b_{b H} \cdot\left(\dot{y}_{n}-\dot{y}_{h}\right)
\end{aligned}
$$

The conditions for the solution of the given equation result from the force balance on the heald, and they take into account an allowance in the heald attaching on the carrying wire. $\mathrm{H}, \mathrm{H} 1, \mathrm{D}$ and $\mathrm{D} 1$ constants have the values 0 and 1 and they determine which parts of the equation will be applied in the calculation. The solution beginning results from the equation of motion (2). The heald is fixed to the upper carrying wire and its bottom part is inserted into the damping element.

$$
\begin{aligned}
& \ddot{y}_{n}=\frac{T_{o}}{m_{n}}-g+\frac{k_{n H}}{m_{n}} \cdot\left(y_{h}-y_{n}\right)+\frac{b_{n H}}{m_{n}} \cdot\left(\dot{y}_{h}-\dot{y}_{n}\right) \\
& +\frac{k_{b D}}{m_{n}} \cdot\left(y_{d}-y_{n}-\phi+\Psi\right)+\frac{b_{b D}}{m_{n}} \cdot\left(\dot{y}_{d}-\dot{y}_{n}\right)
\end{aligned}
$$

The heald detaching from the upper carrying wire takes place at the moment of balance achievement. The heald remains inserted into the damping element at this moment. The equation changes to the following form: 


$$
\begin{aligned}
& \ddot{y}_{n}=\frac{T_{o}}{m_{n}}-g+\frac{k_{b D}}{m_{n}} \cdot\left(y_{d}-y_{n}-\phi+\Psi\right)+\frac{b_{b D}}{m_{n}} \cdot\left(\dot{y}_{d}-\dot{y}_{n}\right) \\
& y_{n}=y_{h}+\Psi
\end{aligned}
$$

The heald detaching from the damping element occurs at the moment of equality (4), and the heald relocation takes place between the main beams. The relocation is solved by means of the equation $(5)$.

$$
y_{n}=\frac{T_{o}}{m_{n}}-g
$$

The heald movement before an impact on the carrying wire is damped by the damping element. The relocation is finished if conditions (4) or (6) are fulfilled. Contact of the bottom part of the heald with the damping element attached to the bottom stave is the first potential boundary state. "The condition (4) is fulfilled at this moment. It is the return of the heald to the upper stave carrying wire. The calculation of the heald movement is carried out according to the equation (3).

If the equality is fulfilled (6), the contact of the heald with the damping element attached to the upper carrying wire takes place. The heald motion is solved according to the equation (7) in this case. The heald is pressed into the rubber mass by its bottom end before an impact on the carrying wire. The relative speed of the heald in relation to the carrying wire is decreased by the damping element.

$$
\begin{aligned}
& y_{n}=y_{d}-\Psi \\
& \ddot{y}_{n}=\frac{T_{o}}{m_{n}}-g-\frac{k_{b H}}{m_{n}} \cdot\left(y_{n}-y_{h}-\phi+\Psi\right)-\frac{b_{b H}}{m_{n}} \cdot\left(\dot{y}_{n}-\dot{y}_{h}\right) \\
& y_{n}=y_{h}+\phi
\end{aligned}
$$

If the condition (8) is fulfilled, the heald is caught on the bottom carrying wire and the motion is solved by the equation (9).

$$
\begin{gathered}
\ddot{y}_{n}=\frac{T_{o}}{m_{n}}-g-\frac{k_{n D}}{m_{n}} \cdot\left(y_{n}-y_{d}\right)-\frac{b_{n D}}{m_{n}} \cdot\left(\dot{y}_{n}-\dot{y}_{d}\right) \\
-\frac{k_{b H}}{m_{n}} \cdot\left(y_{n}-y_{h}-\phi+\Psi\right)-\frac{b_{b H}}{m_{n}} \cdot\left(\dot{y}_{n}-\dot{y}_{h}\right)
\end{gathered}
$$

The release of the heald from the bottom carrying wire will start at the moment of the force balance achievement on the heald. The heald is inserted into the damping element at this moment. The equation solution changes to the form (7). Two border states must also be checked here. The first one is a return of the heald to the bottom carrying wire (condition 8 is fulfilled); the second border state is the heald detaching from the damping element (condition 6 is fulfilled).

If the upper part of the heald tears away from the damping element, the shift of the heald between the main beams of the heald shaft occurs. The shift will be solved by means of the equation of motion (5). In the case of fulfilment of the condition
(6), the heald motion solution will take place during the first phase according to the equation of motion (7). If the condition (4) is fulfilled, the heald motion is solved by the equation of motion in form (3).

The effect of the thread eyelet is included in the calculation by means of the following conditions:

$$
\begin{aligned}
& \left|y_{n}\right| \leq \frac{\vartheta}{2} \Rightarrow y_{O}=0 \\
& y_{n}>\frac{\vartheta}{2} \Rightarrow y_{O}=y_{n}-\frac{\vartheta}{2} \\
& y_{n}<-\frac{\vartheta}{2} \Rightarrow y_{O}=y_{n}+\frac{\vartheta}{2}
\end{aligned}
$$

The initial conditions of the solution proceed from the presumption that the heald is entrapped on the upper supporting wire, and both its velocity and acceleration are identical to those of the upper supporting wire. The solution of individual mathematical models has been realised by means of derived software. The solution of compiled differential equations describing the shedding motion coupled with an analysis of the movement of heald during the weaving cycle has been affected by the Runge-Kutta method of the fourth order. During the calculation, the courses of the principal kinematic and force quantities of the system have been studied.

The control algorithm of the calculation checks the position of the heald with respect to the supporting wire of the heald shaft. As mentioned above, six possible states can arise, which have been studied and on the basis of which the calculation of the movement of the heald has been realised.

An example of calculated dependencies is given in the Figure 3 -5 , showing the principal kinematic courses of the supporting wire and of the heald. The calculation has been realised for the velocity of the shedding motion $300 \mathrm{rpm}$.

We will use the results of the analysis of the design solution of the heald attaching without the damping element described in [12] for comparison of the acquired values.

\section{Conclusions}

For generation of an improved mathematical model, the model with substitution of the rigidity of the heald by means of Kelvin-Voigt viscoelastic model has proved suitable. The referred enhancement allows determination of the number and the extent of bounces of the heald from the supporting wire after its transfer between individual supporting wires. In this mathematical model, it is possible to ascertain the moment of separation of the heald from the supporting wire as well as the time of transfer of the heald between main beams of the heald shaft. By means of this model, it is possible to determine the loads exerted upon individual end eyelets of the heald. The effected calculations show a high value of acceleration of the heald produced after its drop upon the supporting wire. The referred model allows analysing a considerable part of designs of the heald shaft that are employed in weaving looms nowadays. 


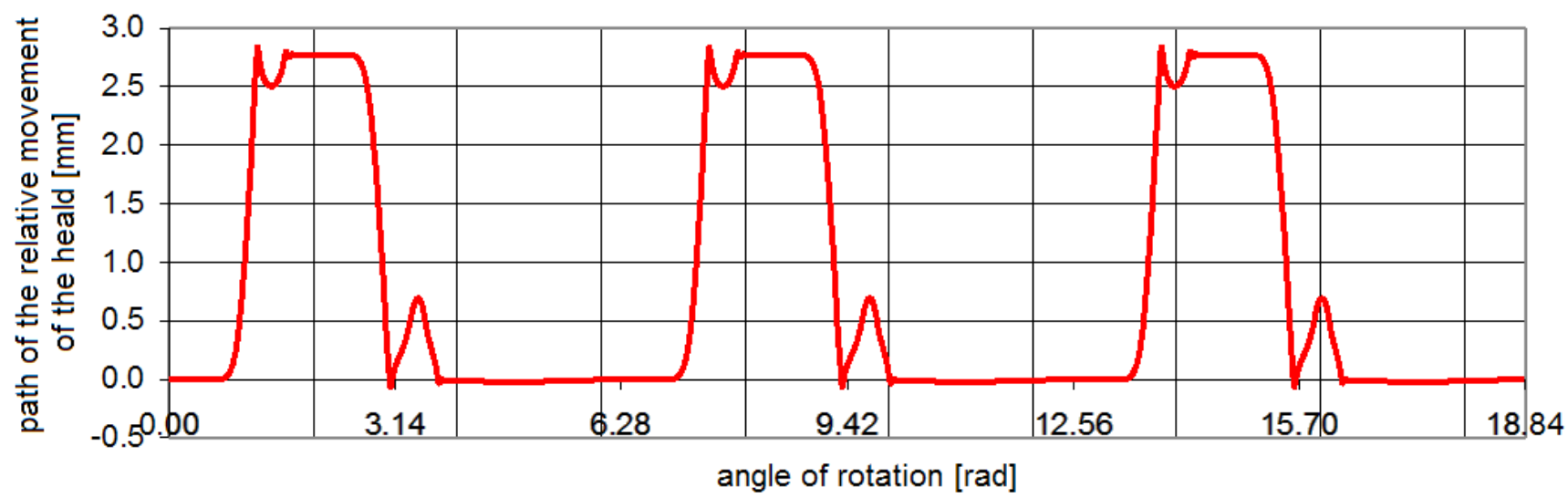

Figure 3 Relative movement of the heald with respect to upper supporting wire operating velocity of the shedding motion $300 \mathrm{rpm}$

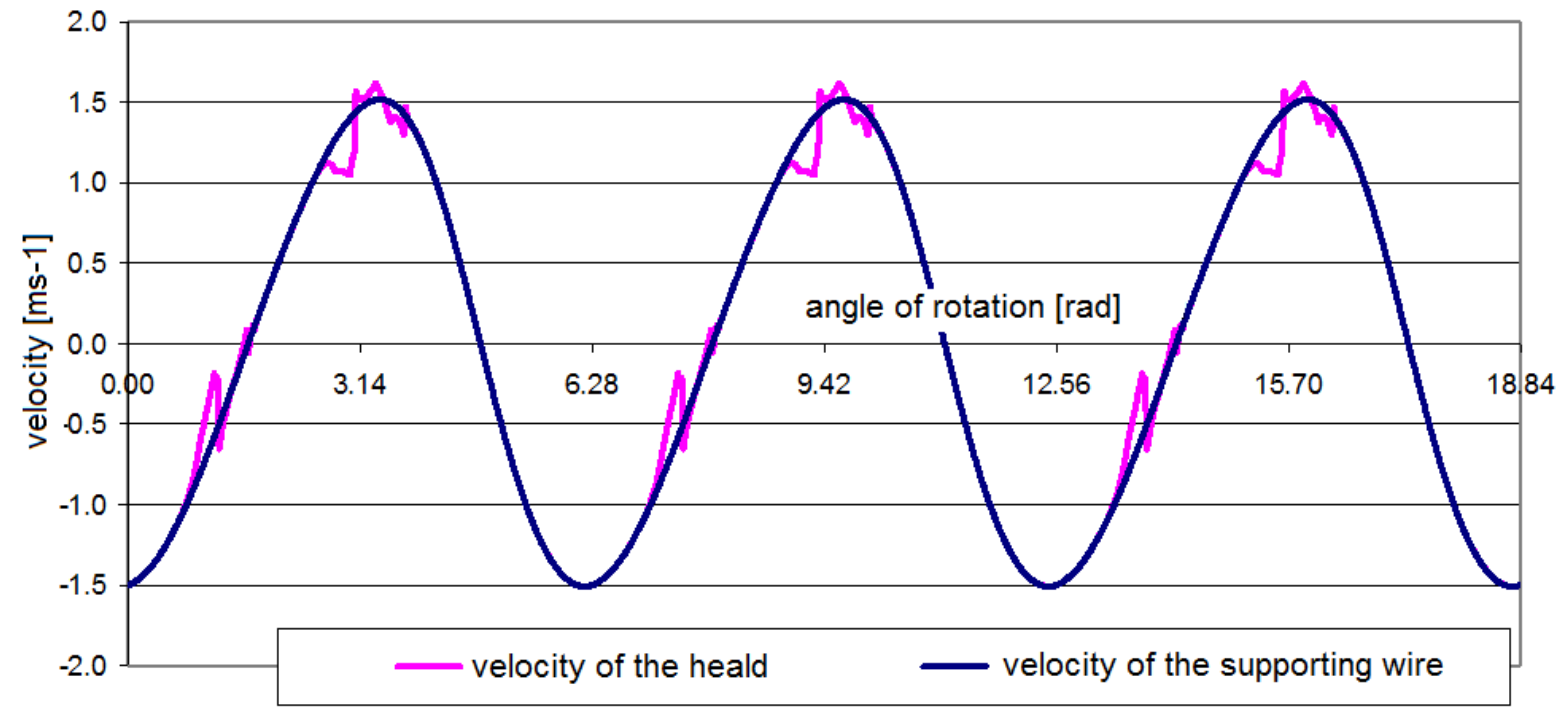

Figure 4 Courses of velocity of the supporting wire of the heald shaft and of the heald, operating velocity of the shedding motion 300 rpm.

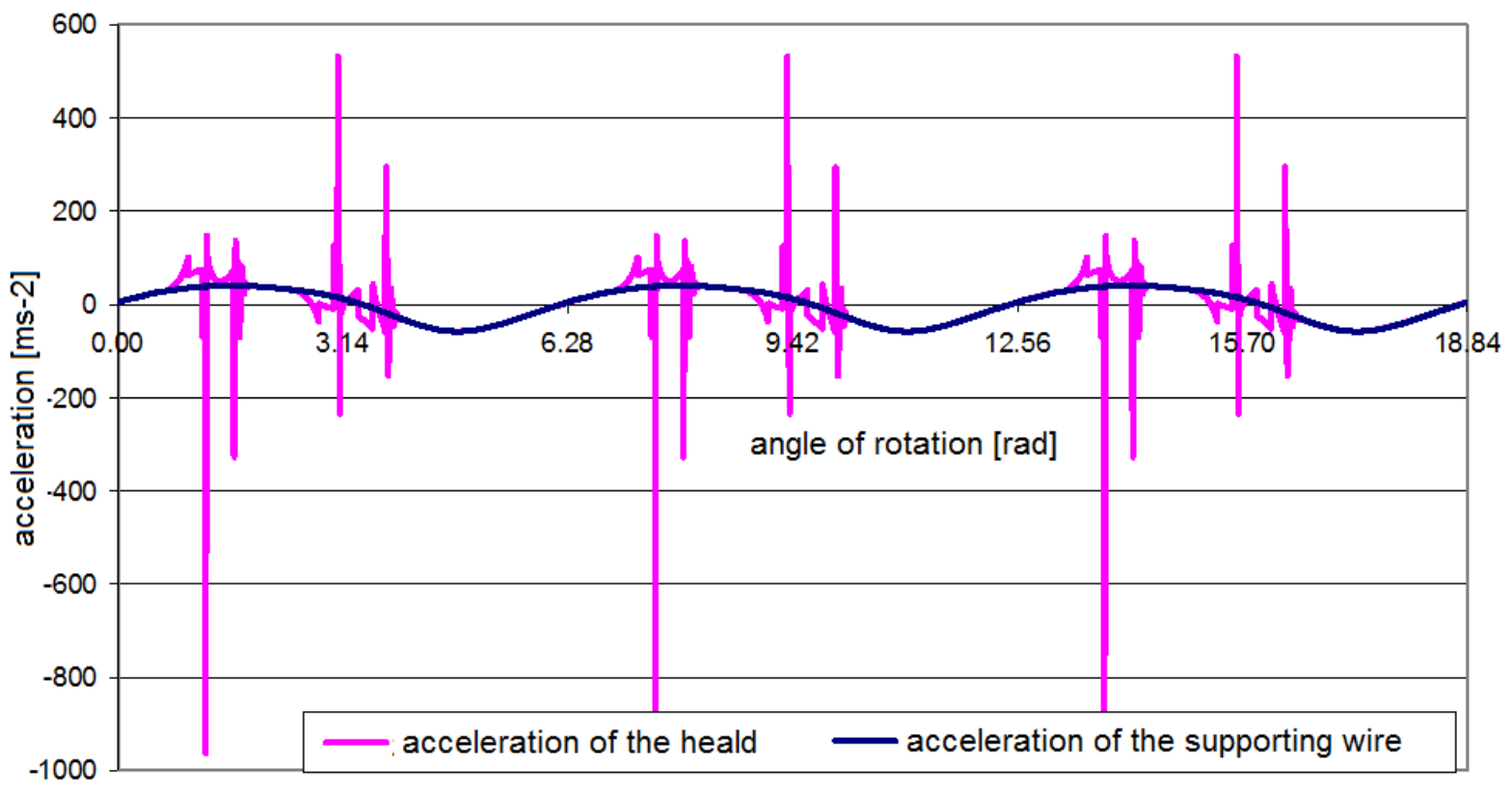

Figure 5 Courses of acceleration of the supporting wire of the heald shaft and of the heald, operating velocity of the shedding motion 300 rpm. 
Table 1. Maximal value of acceleration after its transfer between individual supporting wires.

\begin{tabular}{|c|c|c|c|}
\hline \multirow{2}{*}{$\begin{array}{c}\text { Acceleration of heald after its transfer on upper rod [m } \\
\left.\mathbf{s}^{-2}\right]\end{array}$} & \multicolumn{3}{|c|}{ Shedding motion [rpm] } \\
\cline { 2 - 4 } & $\mathbf{1 5 0} \mathbf{~ r p m}$ & $\mathbf{3 0 0} \mathbf{~ r p m}$ & $\mathbf{4 5 0} \mathbf{~ r p m}$ \\
\hline Heald shaft without damping element & 1220 & 1340 & 1477 \\
\hline Heald shaft with damping element & 746 & 963 & 1066 \\
\hline \multirow{2}{*}{ Acceleration of heald after its transfer on lower rod $\left[\mathrm{m} \mathrm{s}^{-2}\right]$} & & \multicolumn{3}{|c|}{ Shedding motion [rpm] } \\
\cline { 2 - 4 } & $150 \mathrm{rpm}$ & $300 \mathrm{rpm}$ & $450 \mathrm{rpm}$ \\
\hline Heald shaft without damping element & 671 & 906 & 1080 \\
\hline Heald shaft with damping element & 294 & 533 & 711 \\
\hline
\end{tabular}

The model described in this article enables the analysis and optimization of the design solution of the heald attaching to the heald shaft frame. The solution is used by some companies for selected types of heald shafts intended for high-speed weaving looms. This model deals progressively with the damping of the heald impact on the carrying wire by the application of the damping element. The results obtained from this model show a reduction in the number of heald bounces after its transfer between individual supporting wires, compared with a system without a damping element. The use of a damping element brings a considerable reduction in the maximum value of heald acceleration. From the performed analysis, there follows that in case of application of a damping system, the equilibrium of forces on the heald occurs in another moment than in case of preceding models. An important aspect of this solution is the transfer of a part of the load upon the lower supporting wire; due to this fact, the loading of the rods of the heald shaft frame is made more equal.

There are maximum and minimum values of heald acceleration after its impact on the upper and bottom carrying wire determined by the calculation in Table No. 1. If we compare the courses of kinematic quantities acquired by means of the individual mathematical models, we can state that the biggest decrease in acceleration occurs in the case of the application of the damping element. This damping influence is more apparent at lower working speed. The percentage value of the acceleration decrease between the maximum values of system with and without damping decreases in the case of increase in working speed.

\section{Acknowledgement}

The paper has been elaborated with financial support of TUL in the framework of specific university research competition.

\section{References}

[1] Recep E., Gülcan Ö., Yildiray T.: Kinematics of Rotary Dobby and Analysis of Heald Frame Motion in Weaving Process. Textile Research Journal, 2008 Vol. 78, No. 12, pp. 1070-1079, USA,

[2] Eren R., Ozkan G., Mehmet Karahan M.: Comparison of Heald Frame Motion Generated by Rotary Dobby and
Crank \& Cam Shedding Motions. FIBRES \& TEXTILES in Eastern Europe. Vol. 13, No. 4 2005, ISSN 1230-3666.

[3] Kapucu, S., Das, M., T., Kilic, A.: Cam Motion tuning of Shedding Mechanism for Vibration Reduction of Heald frame. Gazi University Journal of Science - Volume 23, Issue 2, 2010, Pages 227-232. Turkey

[4] Abdullah G., Hasçelik B., Palamutcu S., Soydan A.S.: Synthesis Work About Driving Mechanism Of A Novel Rotary Dobby Mechanism, Tekstil ve Konfeksiyon, Volume 20, Issue 3, 2010, pages 218-224. Turkey

[5] Terentyev, V.I., Smirnov, B.N.: Dynamics of a shedding mechanism with flexible links. Izvestiya Vysshikh Uchebnykh Zavedenii, Seriya Teknologiya Tekdtilnoi Promyshlennosti - Issue 2, 2011, Pages 80-83. Russia

[6] Korolev, P.A., Lohmanov, V.N.: Kinematics of connections of the shedding mechanism of a circular loom TKP. 110-U. Izvestiya Vysshikh Uchebnykh Zavedenii, Seriya Teknologiya Tekstilnoi Promyshlennosti - Issue 4, 2011, Pages 116-119. Russia

[7] Mukras S., Kim N. H., Mauntler N. A., Schmitz T. L., Sawyer W. G.: Analysis of planar multibody systems with revolute joint wear, Wear, Volume 268, Issues 5-6, 11 February 2010, Pages 643-652, ISSN 0043-1648

[8] Tian Q., Zhang Y., Chen L., Yang J.: Simulation of planar flexible multibody systems with clearance and lubricated revolute joints. Nonlinear Dynamics, Volume 60, Issue 4, June 2010, pp 489-511

[9] lores P., Koshy C. S., Lankarani H. M., Ambrósio J., Claro J. C. P.: Numerical and experimental investigation on multibody systems with revolute clearance joints. Nonlinear Dynamics, Volume 65, Issue 4, September 2011, pp 383398

[10] Mrázek, J.: Theoretical analysis of dynamics four-bar beat up mechanisms of a loom. In.: Mechanism and machine theory, Pergamon Press, 1992, USA

[11] Bílek, M., Mrázek, J.: Dynamic Stress of Heald Shaft of Weaving Looms. Vlákna a textil, 1998, č.3, s. 131-134, Slovakia.

[12] Bílek, M., Skřivánek J.: Mathematical modeling of the system shedding motion - heald - warp, AUTEX Research Journal, Vol. 14, No. 2, June 2013, Pages 42-46. ISSN 1470-9589. Poland

[13] Bílek, M.; Beran, J.: Dynamický model prošlupního mechanismu tkacího stroje. In. Aplikovaná mechanika 2001. Plzeň: Západočeská univerzita v Plzni, 2001, s. 1117. 
[14] Beran J.; Bílek M.: Matematické modelování základních mechanismů tkaciho stroje. In TRANSFER 2000. Trenčín: TnU, Slovensko, 2000. s 25-30.

[15]Akamura, T., Kinari, T., Shimokawa, T., Miyashita, D., Mochizuki, Y., Shintaku, S.: Jumping behavior of heald in a shedding motion of loom. Journal of Textile Engineering , Volume 52, Issue 2, 2006, Pages 87-92. Japan

[16] Bílek, M., Kovář, Š.: Record of the movement of heald in the weaving loom. In IX. International Conference on the Theory of Machines and Mechanism in association with the II. CEACM Conference on Computational Mechanics 2004. Liberec : TUL, 2004, pp. 87-92.

[17] Bílek, M., Kovář, Š.: Mathematical model of the heald shaft of the weaving loom. Buletinul institutului polytehnic din Iaşi. Technical University of laşi, 2007 laşi, fasc. 5, volume 1, pp. 375-382. Romania

[18] Hong Jun, C., Li Jun, L. Analysis on Warp's Frictional Movement in the Heald Eye during Weaving Process.
Advanced materials Research Volume 175-176, January 2011, Pages 490-495.

[19] Bílek, M.: Analysis of Head Motion during of Weaving Process, XI. International Conference on the Theory of Machines and Mechanisms, September 4-6. 2012, Liberec, Czech Republic, p. 367-373, ISBN 978-94-0075124-8, Springer Science Business Media Dordrecht

[20] Tumajer P., Ursíny P., Bílek M., Moučková E.: Use of the vibtex vibration system for testing textiles, AUTEX Research Journal, Vol. 11, No2, June 2011, ISSN 14709589,

[21] Tumajer P., Ursíny P., Bílek M., Moučková E.: Research Methods for the Dynamic Properties of Textiles. FIBRES \& TEXTILES in Eastern Europe 2011, Vol. 19, No. 5 (88) pp. 33-39.

[22] Tumajer P., Ursíny P., Bílek M., Moučková E., Pokorná M.: Influence of structure of the yarn on mechanical characteristics of yarns exposed to dynamic stress, Autex Research Journal, Volume 12, Issue 2, June 2012, Pages 44-49 